\title{
To march in or not to march in
}

\section{To the Editor:}

In Nature Medicine's May editorial, "March on, not in" (Nat. Med. 17, 515, 2011), the journal asserts that ending patent exclusivity for Fabrazyme and introducing generic competition in the US "could do far more harm than good." Yet, judging by the situation outside the US, where a competitive market already exists, this position is misplaced.

In Europe and elsewhere, people with Fabry's disease already have access to an alternative drug called Replagal (agalsidase alfa), manufactured by UK-based Shire Corporation, that is currently sold in 45 countries-including Canada, Japan, Brazil, China and all 27 members of the EU-but has not yet been approved by the US Food and Drug Administration. Competition is so vigorous in European and other global markets that Shire recently posted record sales of Replagal, with the drug pulling in $\$ 351$ million last year (compared to $\$ 188$ million in 2010 worldwide sales for Genzyme's Fabrazyme). Despite the competitive arena for enzyme replacement therapy for patients with Fabry's disease, however, the harms alleged in the editorial have not occurred.

Ironically, the competitive global market is directly responsible for fueling drug shortages in the US. To make up market share lost to Shire as people switch from untested low-dose versions of Fabrazyme to Replagal, Genzyme is now exporting much of its limited full-dose Fabrazyme supplies overseas. Indeed, in April 2010 Genzyme abandoned its rationing plan in European and other foreign markets but not in the US. Consequently, most affected individuals in US-who do not have the option of switching medicines-are now receiving either dangerous, unapproved low doses of Fabrazyme or no drug treatment at all. Europe, in contrast, continues to receive full doses of Fabrazyme sufficient to treat up to 400 people (Mol. Genet. Metab. 102, 99-102, 2011).

Genzyme, for its part, has been less than forthcoming regarding its apparent double standard for treatment recommendations for Fabrazyme. During the latest supply disruption reported in March, Genzyme wrote in a letter to patients that "to help share the impact of this loss, some Fabrazyme that was originally destined for patients treated in the US will be diverted to patients elsewhere," presumably to ensure that full doses are available overseas. Yet the company then blamed US doctors for the rationing plan. "Physicians are managing the limited supply of Fabrazyme in Europe differently than in other markets like the US," a Genzyme spokesperson told the Pharmalot news site in May. However, to the best of my knowledge, U.S. physicians have nothing to do with the supply being managed differently from its European counterpart. In fact, just like European doctors, US physicians prescribe the full, FDA-approved dose of $1 \mathrm{mg} \mathrm{kg}^{-1}$ every two weeks. However, Genzyme will not ship these full doses every two weeks to the US patients. As a result, Genzyme de facto uses its patent monopoly to dictate how American doctors treat US patients with Fabry's disease, in contrast to European physicians whose full-dose prescriptions are honored.

As to whether breaking Genzyme's patent is premature, it is now apparent that if a march-in had been granted over two years ago when the shortage first occurred, Americans would probably now have the same competitive market benefits as Europeans. Absent a few truly brave patients with Fabry's disease willing to speak up and demand access to this life-saving drug, it is unlikely that Nature Medicine (or anyone else) would have even discussed this issue with any gravity. Moreover, it is only through patient actions that information has come to light about Genzyme's dubious business practices and preferential treatment standards for patients with Fabry's disease of different nationalities.

Here in the US, the Fabrazyme patent provides no public benefit. Even though American taxpayers paid for the development of the drug, and American patients have paid monopolistic prices for the drug, Americans are not being saved by the drug, because full doses are being exported to maintain market share in Europe, even though an alternative is available. Thus, it seems disingenuous for the editors of Nature Medicine to argue that "messing with patent rights" is a greater evil than promoting competition and access to drugs, especially when Europeans have such a competitive market where they enjoy full-dose treatment and alternative medication because of just such competition.

\section{COMPETING FINANCIAL INTERESTS}

The author declares no competing financial interests.

\section{Allen Black Jr}

Law Office of C. Allen Black, Allison Park, Pennsylvania, USA. e-mail:allenblack@patentlawyersite.com

\section{Nature Medicine replies:}

We thank Dr. Black for his thoughtful correspondence. Although we agree that alternate drug products could benefit patients with Fabry's disease in the US, we continue to think that marching in on Genzyme's intellectual property is not necessarily the way to achieve a competitive marketplace.

Shire's application for US approval of Replagal does not hinge on the patents related to Fabrazyme. Last year, the US Food and Drug
Administration requested additional data about Replagal to confirm comparability between two types of manufacturing procedures. Shire subsequently withdrew its biological license application and, according to a company spokeswoman, plans to make a decision about a new application later this year. This process would not be affected by any march-in order, were one granted.

Meanwhile, Genzyme continues to tackle its contamination problems, and the company expects to have full supplies of Fabrazyme by the end 